\title{
INFLUENCE OF FIBER DEPOSITION AND ORIENTATION ON STRESS DISTRIBUTION IN SPECIMENS PRODUCED USING 3D PRINTING
}

\author{
MAJKO Jaroslav', HANDRIK Marián', VAŠKO Milan¹, SÁGA Milan¹ \\ ${ }^{1}$ University of Žilina, Faculty of Mechanical Engineering, Department of Applied Mechanics, \\ Univerzitná 8215/1, 01026 Žilina, Slovak Republic, e-mail: jaroslav.majko@fstroj.uniza.sk, \\ marian.handrik@fstroj.uniza.sk,milan.vasko@fstroj.uniza.sk,milan.saga@fstroj.uniza.sk
}

\begin{abstract}
Continuous fiber fabrication technology, developed by Markforged and used in MarkTwo printers, allows using of reinforcing fibers, which improve mechanical properties of produced parts. The technology enables choosing of two fiber deposition strategies: isotropic fiber fill and concentric fiber fill. With the isotropic fiber fill, there is an option to set up various fiber angles in each layer. The article is focused on stress distribution analysis using FEM in a matrix and individual reinforcing fibers of specimens loaded to uniaxial tension. Main observed parameters are stresses in matrix and fiber and usage of the reinforcing material.
\end{abstract}

KEYWORDS: carbon fiber, 3D printing, tensile test, MATLAB, ADINA

\section{Introduction}

Additive manufacturing is a process of joining material layer upon layer with primary objective to create objects from a 3D model [1]. The most widespread technology of additive manufacturing is $3 \mathrm{D}$ printing. The technology is based on deposition of material. In contrast to conventional manufacturing technologies, it has many advantages such as low production costs, short manufacturing cycle time, etc. [2]. The development of 3D printing began more than 30 years ago. The first developed method was stereolitography. This method works on principle of photopolymerization. This phenomenon occurs when resin is exposed to UV light [3]. Recently, Fused Filament Fabrication (FFF) is the most common 3D printing method [4]. The thermoplastic filament is fed to the printing head, which is equipped with a nozzle. In the nozzle, the filament is heated to the melting temperature. The printer head moves on the path predefined by the G-code, and the melted material is deposited to specified locations $[5,6]$. Subsequently, melted material solidifies and creates bonding with previous deposited layers. The FFF method advantages are low cost production of prototypes, customization and relatively rapid manufacturing of objects $[2,7]$. Printing resolution depends on fiber diameter limitations [8]. Other disadvantages are poor surface roughness [9] and anisotropic properties of printed objects [5].

Thermoplastics are a suitable material for 3D printing because the influence of temperature changes in the printing process on their mechanical properties is negligible [10]. In order to achieve mechanical properties similar to materials such as steel and aluminium, composites are interesting materials for many industrial sectors [11]. The mechanical properties of composites are better than the mechanical properties of materials which comprise them [12]. Except for conventional methods, FFF and stereolithography printing methods also allow production of composites [2].

MarkForged developed Continuous Fiber Fabrication (CFF) technology which is based on the principle of reinforcing thermoplastics with continuous fibers. It is an augmented FFF 
method; continuous fiber is deposited using a second nozzle [13] with the objective to achieve better mechanical properties of the $3 \mathrm{D}$ printed object. This modification of printing technology was implemented because short fiber reinforced thermoplastic composites have better mechanical properties than non-reinforced thermoplastics [14] but do not achieve the mechanical properties of conventionally produced composites [15].

The working principle of CFF printing method allows selecting of various fiber deposition methods in each layer of printed part. Therefore the assessment of the selected specimens for tensile testing reinforced with different fiber fill types was performed using FE program ADINA to observe the influence of fiber deposition to stress distribution in the specimen. The formation of stress concentrations in the specimens is consequence of inappropriate fiber deposition in the composite structure. The stress concentrations lead to premature failure of the specimen and affect the results of experimental measurements.

\section{Preparation and simulation of tensile test using FEM}

The appropriate shape of 3D printed specimens for tensile testing has not been defined yet. Therefore, the simulation of the common specimen shape types was performed with regard to stresses in matrix and material usage.
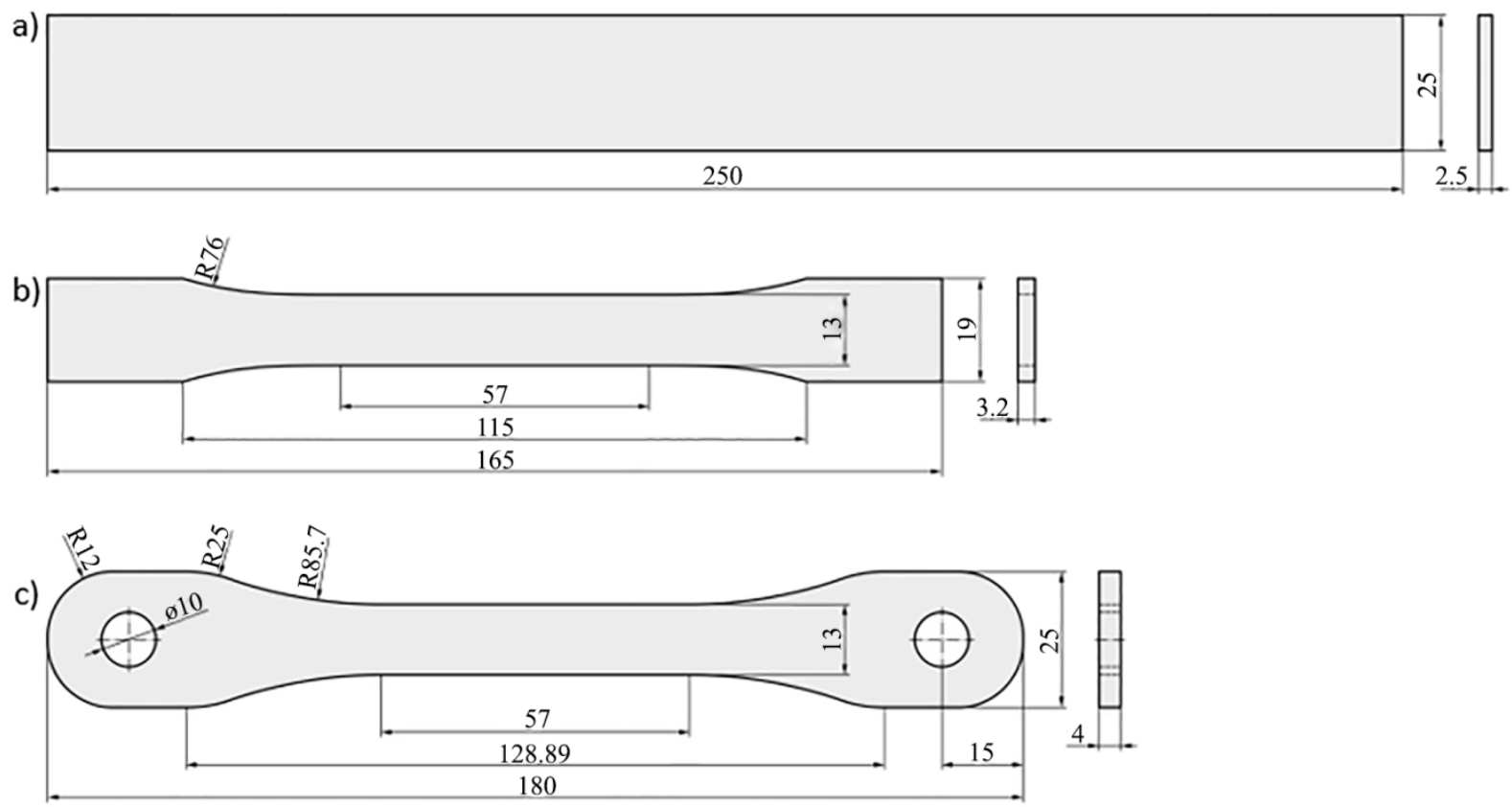

Fig. 1 Assessed specimen shapes

The first assessed specimen shape was designed according to standard ASTM D3039 [16], which is specified for conventionally produced reinforced composites (Fig. 1a). The second specimen shape known as dog-bone was defined in ASTM D638-14 (Fig. 1b) [17]. This standard is given for plastics. The last specimen was a modified ASTM D638-14 specimen shape (Fig. 1c). The modifications of geometry were proposed in study [18] and consist of rounding at the both ends of specimen and holes for attachment.

The specimen geometry was created using the CAD program CATIA (CATIA V5, Dassault Systems, Waltham, MA) and saved as stereolitography file. Subsequently, generated stl file was imported to the program Eiger developed by printer manufacturer MarkForged. The program divided each specimen to equally thick layers. The specimens were reinforced with carbon fiber. 
The specimen shape defined by standard ASTM D3039 [16] was divided into 20 layers. Twelve layers of them were reinforced with continuous fiber. The fiber deposition was isotropic with three concentric rings (Fig. 2).

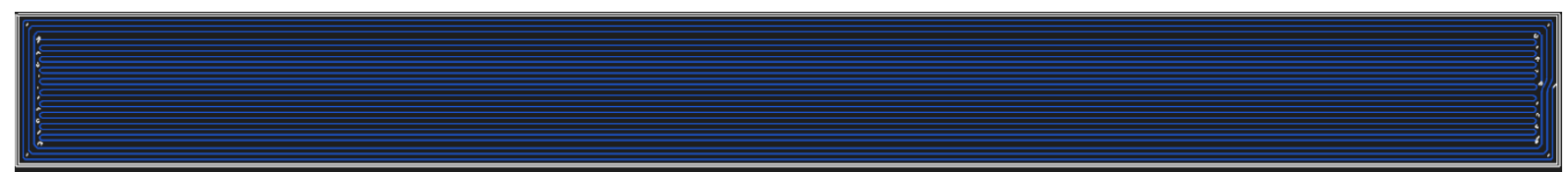

Fig. 2 Fiber deposition in specimen according to ASTM D3039 [16]

The slicing software Eiger divided the second specimen (ASTM D638-14) into 26 layers. This specimen shape was reinforced with various type of fiber deposition. Firstly, the fiber fill type was isotropic with three concentric fiber rings (Fig. 3a). Secondly, unidirectional fiber deposition was applied without concentric rings (Fig. 3b). The last case was reinforcing of the specimen with solely three concentric rings (Fig. 3c). In each case, the specimen was reinforced with fiber in 18 layers.

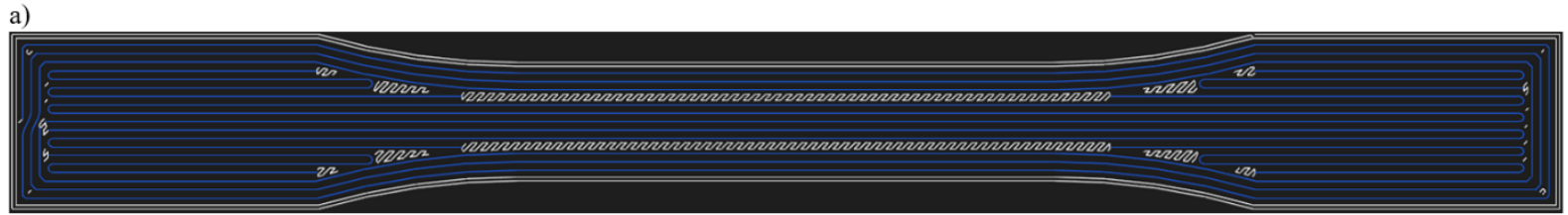

b)

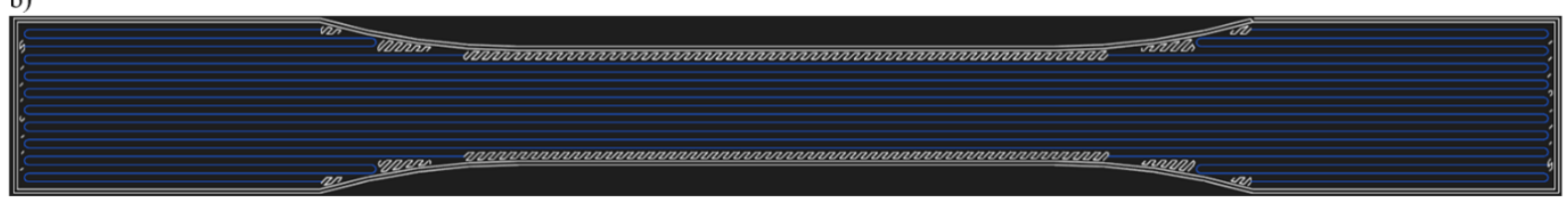

c)

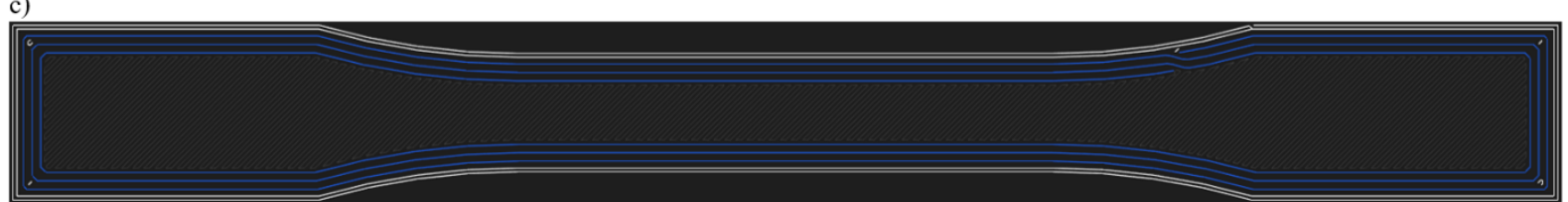

Fig. 3 Fiber deposition in specimen according to ASTM D638-14 [17]: a) isotropic deposition and three concentric rings, b) unidirectional fiber deposition, c) three concentric rings

Finally, the shape of the last specimen was adjusted to the shape of the previous specimen. The specimen was reinforced with three concentric rings and two concentric rings around the holes in 24 layers (Fig. 4).

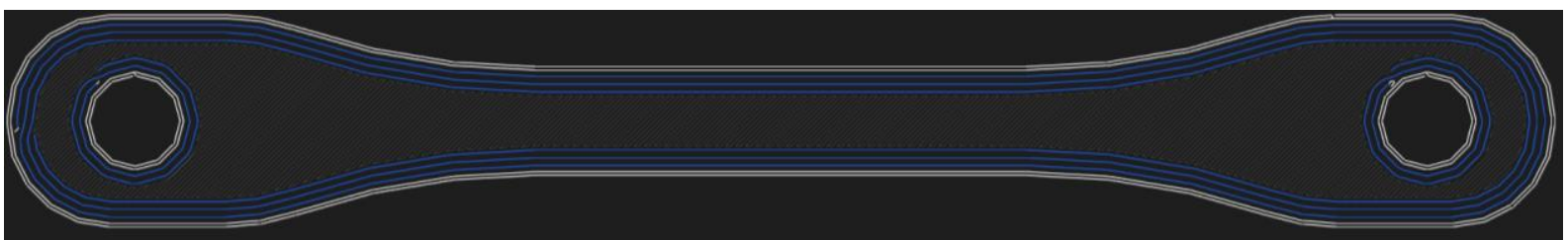

Fig. 4 Fiber deposition in specimen according to study [18]

The tensile testing of these specimens was simulated in the program ADINA. The simulation of continuous fiber reinforced thermoplastic composites is viable using rebar elements, which allows simulating of continuous fiber deposited in matrix.

The fiber deposition was determined from the slicing software Eiger and the generation of models for finite element method program was performed using the program MATLAB. 
The material properties were specified as a multilinear material model. Mechanical properties of matrix and carbon fiber were defined from experimental measurements. The more precise description of modeling and simulation is specified in another article with the title Influence of the shape of the test specimen produced by 3D printing on the stress distribution in the matrix and in long reinforcing fibers.

\section{Stress distribution analysis}

This section discusses stress distribution in specimens during the tensile test. The assessment was performed on outer layers of matrix and outer layers reinforced with carbon fiber (Figs. 5 to 9). In addition, the usage of material was considered.

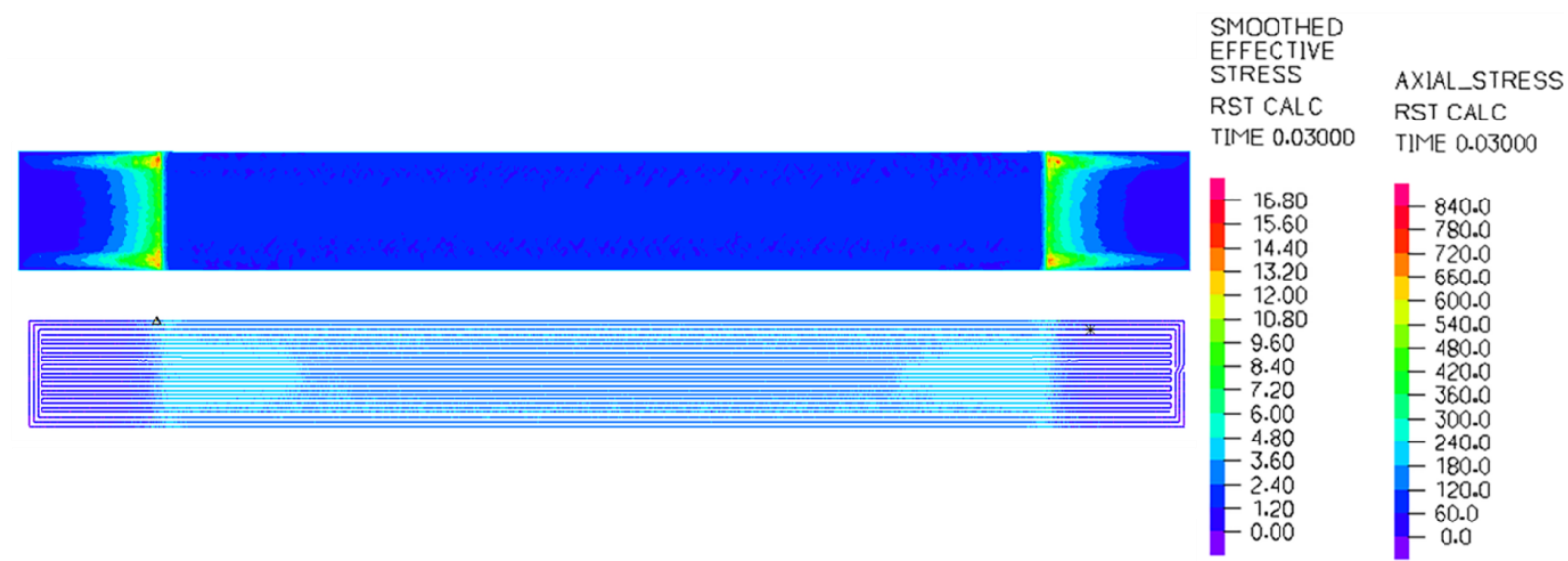

Fig. 5 Stress distribution in matrix and fibers of the specimen according to ASTM D3039. The upper figure displays effective smooth stress in matrix. The bottom figure shows axial stress in reinforcing fibers.

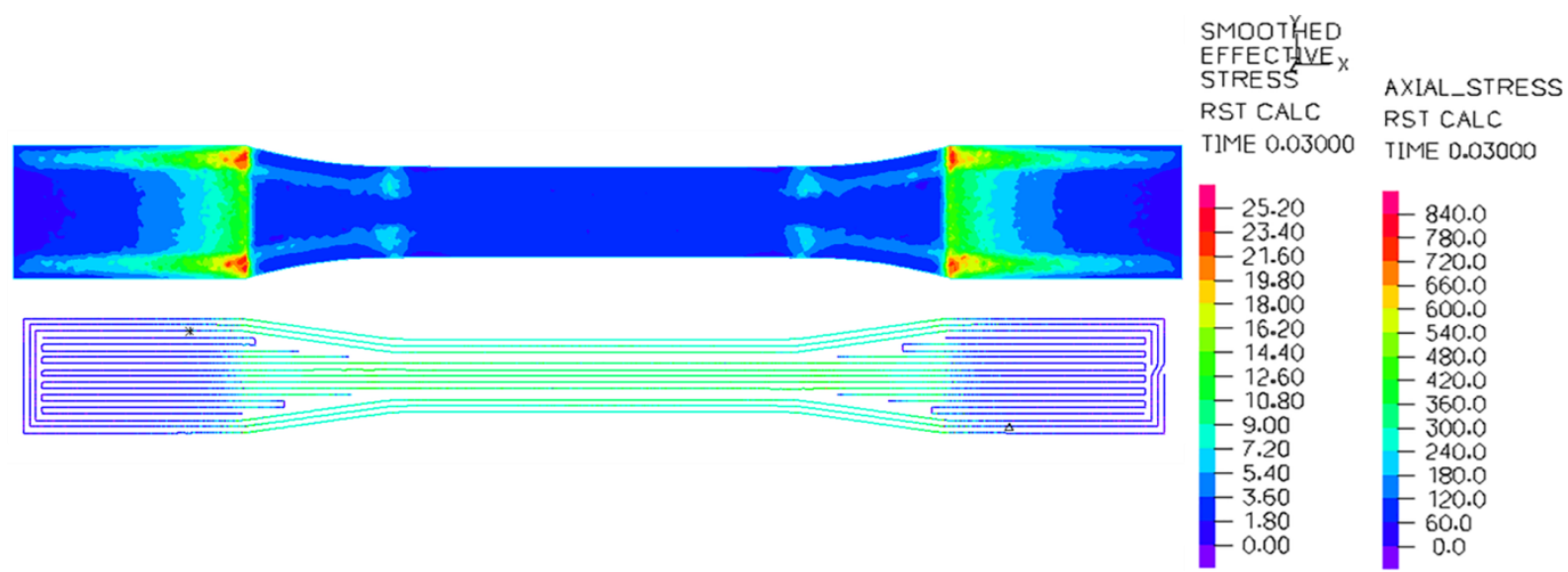

Fig. 6 Stress distribution in matrix and fibers of specimen according to ASTM D638-14. Specimen is reinforced with isotropic fiber fill and three concentric rings. The upper figure displays effective smooth stress in matrix. The bottom figure shows axial stress in reinforcing fibers. 


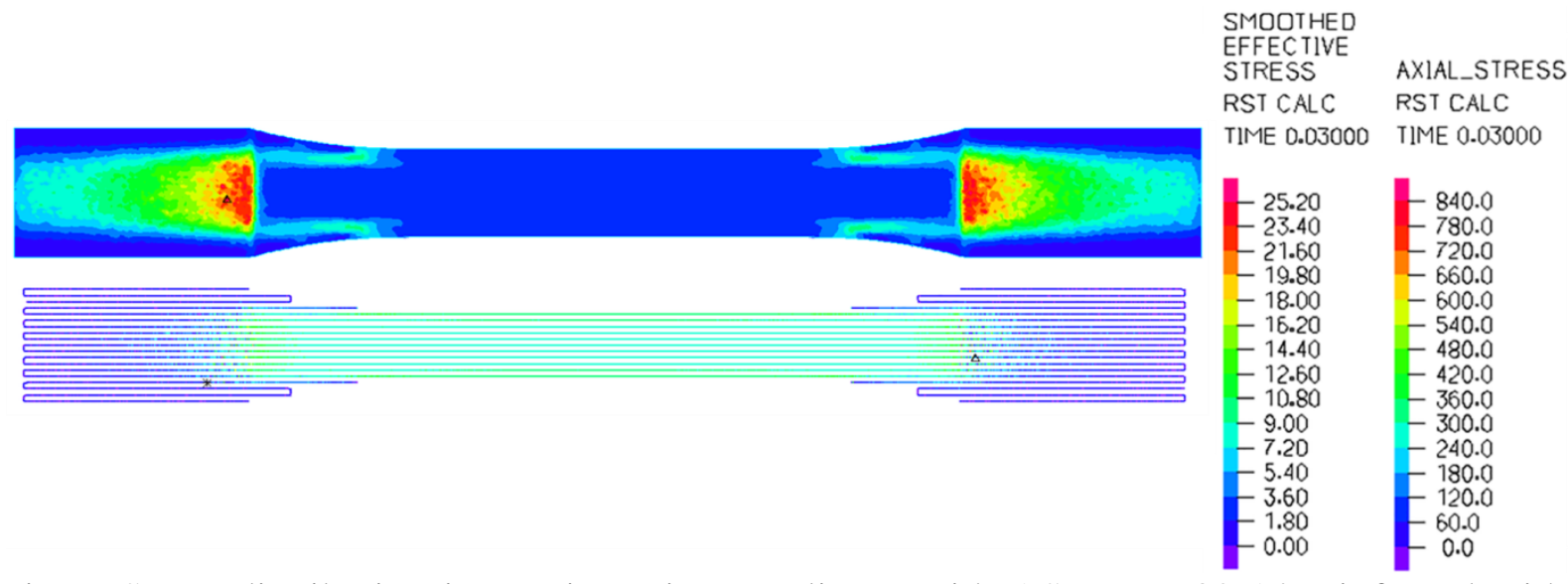

Fig. 7 Stress distribution in specimen in compliance with ASTM D638-14 reinforced with unidirectional fiber deposition. The upper figure displays effective smooth stress in matrix. The bottom figure shows axial stress in reinforcing fibers.

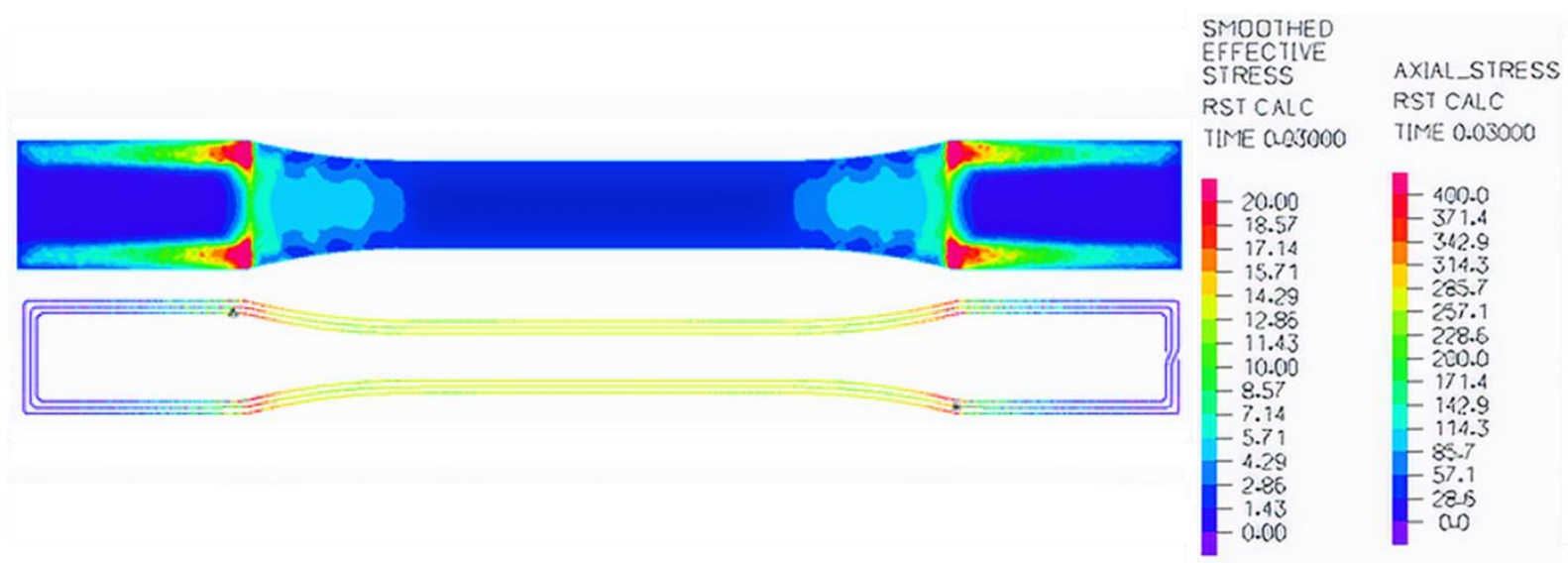

Fig. 8 Stress distribution in specimen in compliance with ASTM D638-14 reinforced with three concentric fiber rings. The upper figure displays effective smooth stress in matrix. The bottom figure shows axial stress in reinforcing fibers.

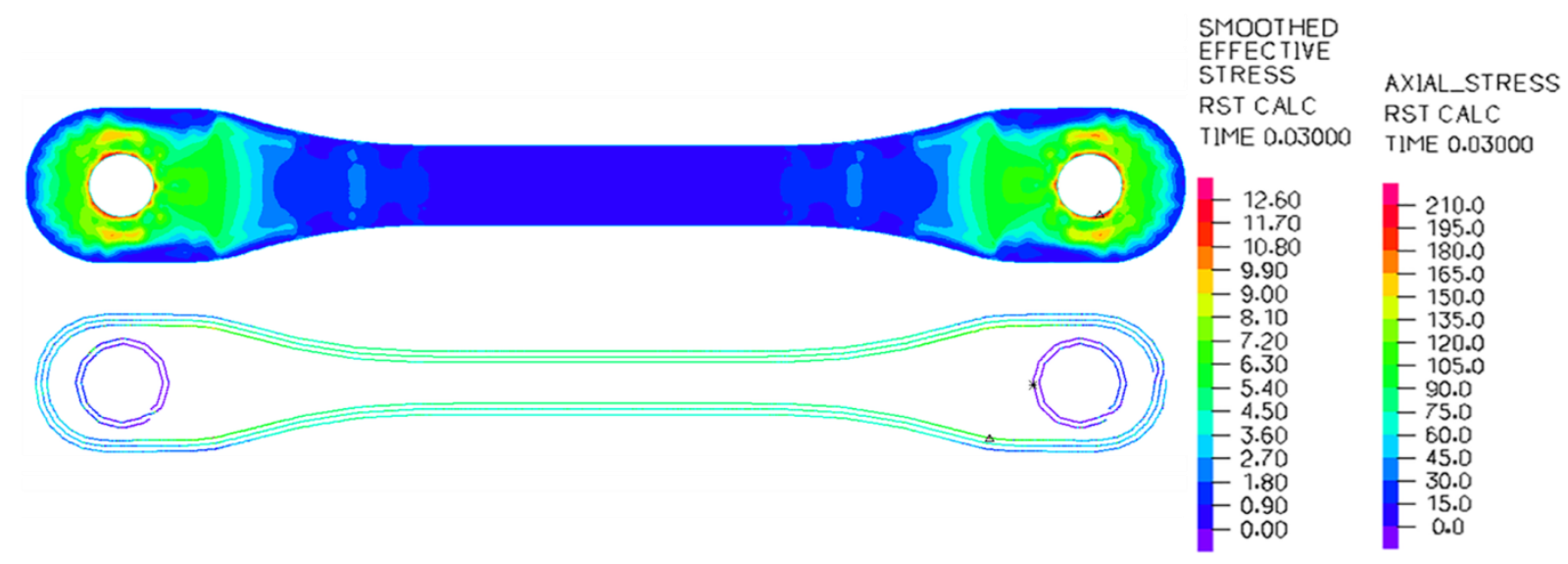

Fig. 9 Stress distribution in specimen according to study [16]. The upper figure displays effective smooth stress in matrix. The bottom figure shows axial stress in reinforcing fibers.

The outer layers of matrix in specimens have the maximum stresses near to attachment. Subsequently, this loading is transmitted from the matrix to the fiber. The fiber has a significant influence on specimen tensile strength. 
The specimen according to ASTM D3039 has the maximum stresses in matrix approximately $16.8 \mathrm{MPa}$ in gripping region. Maximum stress in fibers is $840 \mathrm{MPa}$. The material usage is $15.88 \mathrm{~cm}^{3}$.

The dog-bone specimen in compliance with standard ASTM D638-14 reinforced with isotropic fiber fill and three concentric fibers has the maximum stress in fibers $840 \mathrm{MPa}$. The fiber deposition leads to occurrence of stress concentrations in the shoulder region. Therefore the maximal stress in matrix is $25.2 \mathrm{MPa}$. The total material usage is $8.7 \mathrm{~cm}^{3}$.

The third assessed specimen, designed according to ASTM D638-14, was reinforced with unidirectional fiber deposition in 18 layers. Maximal stress values are equal to the previous specimen. In the ends of fibers are localized maximal shear stresses [10], which affect occurrence of stress concentrations in shoulder region of specimen. Total quantity of material needed for printing of this specimen is $8.92 \mathrm{~cm}^{3}$.

The specimen in accordance with ASTM D638-14 reinforced with three concentric fiber rings has the maximum stress on outer layers of matrix $20 \mathrm{MPa}$, which is influenced by fiber deposition in curvature regions of specimen. Maximal stress in fibers is $400 \mathrm{MPa}$. The material usage was $9.12 \mathrm{~cm}^{3}$. In this case, the number of reinforcing fibers is different in comparison to previous specimens. The fact has a significant influence on the resultant strength of the specimen. Therefore, lower loading in the computational process was applied, which results in lower values of stress in the structure.

The final specimen was according to standard ASTM D638-14 geometry with the proposed adjustments from study [18]. The maximum stress in matrix is approximately $12.6 \mathrm{MPa}$ and occurs near the holes for gripping on both ends of specimen. Rounding of edges reduce stress concentrations in the shoulder regions. In this region is localized maximal stress in fiber approximately $218 \mathrm{MPa}$. The total material usage is $12.88 \mathrm{~cm}^{3}$.

\section{CONCLUSION}

The maximum stresses in matrix occur near the attachments of specimens. Except for a specimen with a rectangular shape, the stresses are influenced by right angles in specimen geometry and inappropriate placements of fiber ends. These inappropriate adjustments result in premature failure. In terms of production costs, dog bone specimen (ASTM 638-14) appears as the best choice due to low material usage and short production time.

The design of the specimen shape and the embedding of reinforcing fibers is the subject of further research in the field of composite materials produced by $3 \mathrm{D}$ printing.

\section{ACKNOWLEDGEMENTS}

This work was supported by project KEGA No. 037ŽU-4/2018.

\section{REFERENCES}

[1] ASTM F2792-12a Standard Terminology for Additive Manufacturing Technologies, (Withdrawn 2015), ASTM International, West Conshohocken, PA, 2012. Available at: www.astm.org

[2] Goh, G. D., Dikshit, V., Nagalingam, A. P., Goh, G. L., Agarwala, S., Sing, S. L., Wei, J., Yeong, W. Y. "Characterization of mechanical properties and fracture mode of additively manufactured carbon fiber and glass fiber reinforced thermoplastics", Materials \& Design 137, pp. 79 - 89, 2018. DOI: https://doi.org/10.1016/ j.matdes.2017.10.021 
[3] Deckard, C. R. "Method and apparatus for producing parts by selective sintering", United States, US4863538A, 1986.

[4] Parandoush, P., Lin, D. "A review on additive manufacturing of polymer fiber composites", Composite Structures 182, pp. 36 - 53, 2017. DOI: https://doi.org/ 10.1016/j.compstruct.2017.08.088 [DOI]

[5] Varotsis, A. B. "Introduction to FDM 3D printing", [online]. Available at: www.3dhubs.com/knowledge-base/introduction-fdm-3d-printing [Accessed: $12 \quad 03$ 2019].

[6] Dodok, T., Čuboňová, N., Kuric, I. "Workshop programming as a part of technological preparation of production", Advanced in Science and Technology Research Journal 11 (1), pp. 111 - 116, 2017. DOI: https://doi.org/10.12913/22998624/66504

[7] Dimić, A., Mišković, Ž., Mitrović, R., Ristivojvić, M., et al. „The Influence of Material on the Operational Characteristics of Spur Gears Manufactured by the 3D Printing Technology“, Journal of Mechanical Engineering - Strojnícky časopis, 68(3), pp 261270,2018

[8] Dizon, J. R. C., Espera A. H. Jr., A. H., Chen, Q., Advincula, R. C. "Mechanical characterization of 3D-printed polymers", Additive Manufacturing 20, pp. $44-67$, 2018. DOI: https://doi.org/10.1016/j.addma.2017.12.002

[9] Boschetto, A., Bottini, L. "Accuracy prediction in fused deposition modelling", The International Journal of Advanced Manufacturing Technology 73 (5-8), pp. 913 - 928 , 2014. DOI: https://doi.org/10.1007/s00170-014-5886-4

[10] Hyer, M. W. "Stress analysis of fiber-reinforced composite materials", 1st edition, The McGraw-Hill Companies, Singapore, 1998. ISBN 0-07-115983-5.

[11] Ranakoti, L., Pokhriyal, M., Kumar, A. "Natural Fibers And Biopolymers Characterization: A Future Potential Composite Material“, Strojnícky časopis - Journal of Mechanical Engineering 68 (1), pp. 33 - 50, 2018. DOI: 10.2478/scjme-2018-0004

[12] Zapoměl, J., Dekýš, V., Ferfecki, P., Sapietová, A., Sága, M., Žmindák, M. "Identification of material damping of a carbon composite bar and study of its effect on attenuation of its transient lateral vibrations", International Journal of Applied Mechanics 7 (6), 2015.

[13] Crease, A. "3D printer types \& technologies", [online]. Available at: https://markforged.com/learn/3d-printer-types-technologies [Accessed: 1403 2019].

[14] Tekinalp, H. L., Kunc, V., Velez-Garcia, G. M., Duty, Ch. E., et al. "Highly oriented carbon fiber-polymer composites via additive manufacturing", Composites Science and Technology 105, pp. $144-150$, 2014. DOI: https://doi.org/10.1016/ j.compscitech.2014.10.009

[15] Wang, Y. "Mechanical Properties of Stitched Multiaxial Fabric Reinforced Composites From Manual Layup Process", Applied Composite Materials 9(2), pp 81 - 97, 2002.

[16] ASTM D3039/D3039M-17, Standard Test Method for Tensile Properties of Polymer Matrix Composite Materials, ASTM International, West Conshohocken, PA, 2017. Available at: www.astm.org

[17] ASTM D638-14, Standard Test Method for Tensile Properties of Plastics, ASTM International, West Conshohocken, PA, 2014. Available at: www.astm.org 
[18] dos Santos, J. A. P., "Additive manufacturing of thermoplastic matrix composites", Masters Dissertations, Universidade do Porto, 2017. [online] Available at: https://repositorio-aberto.up.pt/bitstream/10216/107982/2/221588.pdf [Accessed: 15.3.2019] 